\title{
Aspectos imunofisiológicos dos controladores de elite frente à infeccão pelo vírus da imunodeficiência humana
}

\author{
Immunophysiological aspects of elite controllers facing \\ human immunodeficiency virus infection
}

RESUMo - Introdução: O Vírus da Imunodeficiência Humana (HIV) é o agente etiológico da Síndrome da Imunodeficiência Adquirida (AIDS). Os sintomas são acarretados pela degeneração lenta e progressiva do sistema imune devido ao ataque aos linfócitos TCD $4^{+}$. Um pequeno percentual da população infectada (1-2\%) é denominado de controlador de elite, ou seja, pessoas que apresentam uma forma branda da infecção, de maneira que conseguem manter a carga viral indetectável por um longo período de tempo, devido a fatores relacionados à infectividade viral e ao sistema imunológico do hospedeiro, sem o uso de antirretrovirais. Objetivo: Descrever os principais mecanismos envolvidos no controle da infecção pelo HIV-1 em pacientes controladores de elite. Metodologia: Trata-se de uma revisão narrativa da literatura cujos dados foram coletados nas bases de dados Pubmed e SciELO. Os critérios de inclusão foram artigos em inglês e português que se enquadraram na temática, publicados entre 1996 e 2019 e foram excluídos artigos que não se enquadraram nesse período. Resultados: Estudos indicam que pacientes controladores de elite são capazes de manter sua carga viral indetectável por um período longo de tempo sem a utilização de tratamentos antirretrovirais. Dentre os mecanismos possivelmente envolvidos, destacam-se a baixa expressão do correceptor CCR5 e o papel dos linfócitos T CD8 ${ }^{+}$ no controle dos linfócitos T CD4 $4^{+}$infectados pelo HIV. Conclusão: Os processos envolvidos no controle da infecção por HIV e na progressão para a AIDS entre os controladores de elite são heterogêneos, logo, estudos adicionais são necessários a fim de esclarecer esses mecanismos.

Palavras-Chave: Síndrome de Imunodeficiência Adquirida; InFeç̧ões Oportunistas Relacionadas com a AIDS; SoropositiviDADE PARA HIV.

Larissa De Oliveira Rosa MARQues $^{1}$

Gabriel Oliveira Santana ${ }^{\text {II }}$ ana Karoline Silva Oliveira ${ }^{I}$ Juliana Menara de Souza MARQUES ${ }^{\text {II }}$

Xisto Sena PassosiI Antonio Márcio Teodoro CorDEIRo SilvaIII

LuCAS Luiz de Lima SilvaI

'Universidade Federal de Goiás (UFG), Goiânia/GO - Brasil

"Universidade Paulista (UNIP)

IIIPontifícia Universidade Católica de

Goiás, Goiânia/GO - Brasil
Abstract - Introduction: The Human Immunodeficiency Virus (HIV) is the etiologic agent of the Acquired Immunodeficiency Syndrome (AIDS). Symptoms are caused by the slow and progressive degeneration of the immune system due to the attack on CD4+ T lymphocytes. A small percentage of the infected population (1-2\%) is called elite controller, that is, people who have a mild form of the infection, so that they manage to maintain an undetectable viral load for a long period of time, due to factors related to viral infectivity and the host's immune system, without the use of antiretroviral drugs. Objective: Describe the main mechanisms involved in the control of HIV-1 infection in elite controller patients. Methodology: This is a narrative literature review whose 
data were collected in Pubmed and SciELO databases. The inclusion criteria were articles in English and Portuguese that fit the theme, published between 1996 and 2019, and articles that did not fit into this period were excluded. Results: Studies indicate that elite controller patients are able to maintain their viral load undetectable for a long period of time without the use of antiretroviral treatments. Among the mechanisms possibly involved, the low expression of the CCR5 co-receptor and the role of CD8+ T lymphocytes in the control of HIV-infected CD4+ T lymphocytes stand out. Conclusion: The processes involved in the control of HIV infection and the progression to AIDS among elite controllers are heterogeneous; therefore, further studies are needed in order to clarify these mechanisms.

Keywords: Acquired Immunodeficiency Syndrome; AIDS-RelaTED OPPoRTUNISTIC INFECTIONS; HIV SEROPOSITIVITY.

\section{INTRODUÇÃO}

A síndrome da imunodeficiência adquirida (AIDS), trata-se de uma doença crônica sem cura, cujo agente etiológico é o vírus da imunodeficiência humana (HIV). De 2007 até junho de 2019, foram notificados no Sinan 300.496 casos de infecção pelo HIV no Brasil, com uma taxa de detecção de 17,8/100.000 habitantes (2018), totalizando, no período de 1980 a junho de 2019, 966.058 casos de AIDS detectados no país. Também em 2018, foram registrados no Sistema de Informações sobre Mortalidade (SIM) um total de 10.980 óbitos por causa básica AIDS (CID10: B20 a B24), com uma taxa de mortalidade padronizada de 4,4/100.000 habitantes. ${ }^{1,2,3}$

Entre as características morfológicas do HIV, está o formato em esfera, com aproximadamente $100 \mathrm{~nm}$. O vírus pertence ao gênero Lentivirus da família Retroviridae, possui o genoma formado por duas fitas simples de RNA, encapsuladas pelo capsídeo viral envolto pela matriz proteica. Dentre suas estruturas destacam-se a glicoproteína gp120, mais externa, e a gp41 que atravessa o envelope viral. Internamente ao envelope encontra-se a proteína p17 e a p24 no cerne/cap- sídeo viral envolvendo as enzimas integrase e protease. ${ }^{1}$

O envelope viral contém em sua superfície as glicoproteínas principais, gp120 e gp41, necessárias para a ligação e a entrada do vírus nas células. Os linfócitos T $\mathrm{CD}^{+}$ são os principais alvos do HIV. Durante a entrada viral, a gp120 reconhece e se liga à molécula CD4, essa ligação desestabiliza a gp120 expondo a alça V3 que interage com o correceptor CCR5 ativando, dessa forma, a gp41, a fim de que aconteça a fusão do envoltório viral com a membrana celular do hospedeiro. Ao entrar na célula, o RNA viral é liberado no citoplasma e imediatamente transcrito de forma reversa em DNA de fita dupla (dsDNA) pela transcriptase reversa (RT) codificada pelo vírus. O dsDNA viral sintetizado se integra ao DNA do hospedeiro por meio da integrase e, assim, a RNA polimerase hospedeira é utilizada para produzir mRNA, que é, então, traduzido em proteínas virais. ${ }^{5}$

No genoma do HIV-1 encontram-se três principais genes que codificam as proteínas estruturais e enzimas virais denominadas: gag, env e pol. O gene gag codifica a poliproteína p55 que, após clivada por proteases virais, origina quatro proteínas estruturais do 
capsídeo chamadas de p6, p9, p17 e p24. O capsídeo que envolve o ácido nucleico viral possui as proteínas $\mathrm{p} 24$, p6 e p9, enquanto a p17 está localizada entre o núcleo proteico e o invólucro chamado de matriz proteica, revestindo a superfície interna da membrana viral. ${ }^{5}$ No HIV-2 os genes gag, env e pol também estão presentes e possuem as mesmas funções no HIV-1, no entanto, apresentam uma composição de aminoácidos e peso molecular diferentes. ${ }^{1,5}$

O gene env, codifica as glicoproteínas gp160, gp120 e gp41. A gp160 é uma proteína precursora que quando clivada, forma a gp120 e gp41. ${ }^{1}$ As glicoproteínas gp120 e gp41 são importantes para a fusão e a ligação aos receptores de HIV nas células do hospedeiro. O gene pol, codifica as enzimas p66 e p51 utilizadas na transcriptase reversa e, assim, consequentemente na replicação viral. A p31 faz a mediação para a integração do DNA viral nas células do hospedeiro, a p10 é uma protease que faz a clivagem dos percursores proteicos e a p66 degrada o RNA original do HIV. Essas proteínas se encontram no núcleo, associadas ao RNA viral. ${ }^{5}$

O HIV é dividido em dois tipos: o HIV-1 e HIV -2. Ambos apresentam o mesmo modelo genético, modo de transmissão, mecanismo de replicação (reprodução) e mesmo desfecho, ou seja, se não tratadas, levam à fase AIDS. O HIV do tipo 1 possui uma alta taxa de mutação e é responsável pela maior parte das infecções pelo vírus no mundo. É subdividido em 4 grupos: M (main/major), $\mathrm{O}$ (outlier), $\mathrm{N}$ (new ou non-M/non-O) e $\mathrm{P}$ (pending the identification of further human cases). O grupo $\mathrm{P}$ foi recentemente identificado e está intimamente relacionado ao SIVgor (Simian Immunodeficiency Virus -
Gorilas), essa nova variante de HIV-1 foi encontrada em uma mulher de Camarões e é diferente dos outros três grupos identificados anteriormente. ${ }^{1,5}$ Dentro do grupo $\mathrm{M}$ está a maior parte das causas de AIDS, sendo divididos em subtipos da letra A a K. Indivíduos infectados pelo HIV do tipo 2 apresentam progressão lenta da infecção, retardo da depleção de células $\mathrm{T} \mathrm{CD} 4^{+}$e menores cargas virais plasmáticas quando comparados aos infectados pelo HIV do tipo $1{ }^{1}$

O HIV-2 é subdividido em 8 grupos: A, B, C, D, E, F, G e H, e apresenta resistência intrínseca aos inibidores de transcriptase reversa não nucleosídeos (NNRTIs), no entanto, os pacientes infectados com HIV-2 devem iniciar o tratamento assim que receberem o diagnóstico, da mesma forma como aqueles infectados por HIV-1. ${ }^{6,7}$

As principais vias de transmissão do vírus envolvem o contato com secreções contaminadas com o vírus, sendo as principais a transfusão sanguínea, o transplante de órgãos, o compartilhamento de materiais perfurocortantes (agulhas e seringas), a transmissão vertical por meio da gestação, a lactação de recém-nascidos, a utilização de instrumentos não esterilizados e o contato sexual. O tratamento da infecção por HIV é feito com a associação medicamentosa de antirretrovirais e por meio de profilaxias para possíveis doenças oportunistas. ${ }^{8,9,10}$

Existem diversos níveis de controle da replicação viral, alguns indivíduos, por exemplo, conseguem se manter estáveis por um longo período de tempo permanecendo assintomáticos, sendo denominados long-term nonprogressors (LTNP). Outros, denominados controladores de elite (elite controllers - ECs), possuem sorologia positi- 
va para HIV, mas são capazes de suprimir o vírus por anos, de maneira que a carga viral se mantém abaixo do valor detectável pelos testes moleculares (< 50 cópias de $\mathrm{RNA} / \mathrm{ml}$ de sangue) sem o uso de antirretrovirais, além disso, esse grupo mantém níveis estáveis de linfócitos CD4. ${ }^{11,12}$ Em média, menos de $1-2 \%$ da população infectada pelo HIV são controladores de elite. ${ }^{13}$

\section{Objetivo}

O presente estudo teve como objetivo a descrição dos principais mecanismos envolvidos no controle da infecção pelo HIV-1 em pacientes controladores de elite.

\section{Procedimentos Metodológicos}

Foram utilizadas fontes de informações bibliográficas eletrônicas para a obtenção dos dados, a fim de descrever os principais mecanismos envolvidos no controle da infecção pelo HIV-1 em pacientes controladores de elite. Os dados foram coletados na base de dados da Biblioteca Nacional de Medicina (Pubmed), Scientific Electronic Library Online (SciELO), e, também, de artigos publicados em revistas nacionais e internacionais. Os descritores em ciências da saúde foram "Síndrome da Imunodeficiência Adquirida"; "Infecções Oportunistas Relacionadas com a AIDS "e "Soropositividade para HIV”. Foram encontrados 40 artigos, porém 28 foram selecionados efetivamente. Os critérios de inclusão foram artigos em inglês e português publicados entre 1996 e 2019, os quais tratam sobre o HIV e AIDS, casos e estudos sobre os controladores de elite e obtenção do controle viral. Foram excluídos do estudo 10 artigos publicados fora do período estabelecido.

\section{RESUlTAdos E DISCUSSÃo}

O HIV inicia o processo de infecção pela etapa de adsorção que consiste na ligação do vírion à superfície da célula alvo do hospedeiro. Esse processo é mediado por interações entre receptores celulares específicos como o CD4 e o domínio extracelular da gp120, uma glicoproteína viral. A participação do CCR5 e CXR4, um grupo de receptores de quimiocinas pertencentes à família de receptores acoplados à proteína $\mathrm{G}$, é fundamental para a entrada do vírus na célula, visto que apenas a interação gp120-CD4 não é suficiente. Assim, após a ligação da gp120 ao receptor CD4 acontecem alterações conformacionais que facilitam a ligação ao correceptor e consequentemente à entrada do vírus na célula alvo.

Após a entrada viral, inicia-se o processo que dá origem às novas proteínas virais. Primeiramente, devido à fusão de membranas, o capsídeo viral entra no citoplasma da célula hospedeira e libera o seu conteúdo (RNA genômico e proteínas virais). No citoplasma acontece o processo de transcrição reversa do genoma viral a fim de produzir um DNA pró-viral, o qual associado às proteínas virais em um complexo núcleo proteico de pré-integração (PIC) é transportado para o núcleo e inserido no cromossomo do hospedeiro. Depois da integração, inicia-se o processo de transcrição, produzindo RNAs virais que serão transportados para o citoplasma para serem traduzidos originando proteínas virais. 
A terapia antirretroviral (TARV) foi estabelecida no final da década de 90, na qual houve uma redução da taxa de mortalidade por AIDS. O curso da infecção pelo HIV é variado entre os pacientes, fato que torna a responsividade ao tratamento muito complexa. A TARV é um método de tratamento baseado na utilização de uma combinação de drogas que atuam em alvos distintos, tornando-a mais efetiva e reduzindo a morbidade e mortalidade dos infectados. O tratamento antirretroviral não erradica as células infectadas, mas auxilia no controle da replicação viral e na reconstituição do pool dos linfócitos $\mathrm{T} \mathrm{CD}^{+}$, prolongando a fase assintomática e retardando a progressão da doença, consequentemente o risco de transmissão é controlado. ${ }^{7,15,16}$

Os medicamentos utilizados são inibidores de transcriptase reversa que se ligam e inibem a enzima transcriptase reversa viral, o que impede a multiplicação do vírus. Existem dois tipos de inibidores de transcriptase reversa, os inibidores de transcriptase reversam não análogos de nucleosídeos (NNRTIs) e os inibidores de transcriptase reversa análogos de nucleosídeos (ITRN), alguns medicamentos ITRN são: zidovudina, didanosina, abacavir, zalcitabina e estavudina. Outra classe de medicamentos antirretrovirais utilizados são os inibidores de protease. A protease é essencial no processo de produção viral, e os inibidores de proteases atuam bloqueando o funcionamento das enzimas proteases em células $\mathrm{T} \mathrm{CD}^{+}{ }^{+}$cronicamente infectadas e, como consequência, são liberadas partículas virais imaturas e não infecciosas. Os medicamentos desse grupo são: lopinavir, ritonavir, indinavir, ritonavir, nelfinavir e amprenavir. ${ }^{\text {? }}$
Ainda existem os inibidores de fusão e os inibidores da integrase. Os primeiros são utilizados para bloquear a entrada do vírus na célula T $\mathrm{CD} 4^{+}$, esse grupo de drogas bloqueia o receptor de quimiocinas 5 (CCR5) presente nos linfócitos $\mathrm{T} \mathrm{CD}^{+}$. O nome comercial dessa droga utilizada é maraviroc. Já os inibidores de integrase, impossibilitam a integração do DNA viral ao genoma do hospedeiro, impedindo a replicação viral. As drogas comerciais utilizadas nesse grupo são denominadas: raltegravir, elvitegravir e dolutegravir. ${ }^{7}$

O HIV provoca a deleção das células T CD4 ${ }^{+}$, e se não houver controle da replicação viral, a infecção pode evoluir para o estágio de AIDS. A intensa replicação viral leva a exaustão celular por excesso de ativação de células do sistema imunológico. Com a persistência de antígeno viral em altos níveis na circulação, as células $\mathrm{T} \mathrm{CD}^{+}$se esgotam e perdem a capacidade de eliminar células infectadas. Além dos altos índices de antígeno viral, a forte ativação imune pró-inflamatória durante a infecção pelo HIV também contribui para o desenvolvimento da exaustão celular. Logo, observa-se a importância de controlar a carga viral e mantê-la a níveis adequados a fim de não comprometer a integridade das células de defesa, principalmente as células T CD $4^{+}{ }^{+13,17,18,19}$

Alguns fatores do hospedeiro atuam no controle da infecção viral de maneira natural, mantendo os níveis de replicação viral baixos. Aproximadamente 7\% dos pacientes infectados pelo vírus, conseguem o controle transitório da infecção por um tempo inferior a 12 meses, após esse período, os fatores do vírus se tornam superiores aos do hospedeiro. ${ }^{20,21}$ Existem casos em que o 
paciente consegue manter o controle viral por mais de 1 ano, adquirindo a chance de obter resultados indetectáveis da replicação viral e se manter por um tempo dessa forma, encaixando-se no grupo dos controladores de elite. Segundo o consórcio internacional de controladores de HIV, pacientes que possuem o vírus da imunodeficiência humana que se mantiveram com cargas virais abaixo de 50 cópias/mL nos últimos 12 meses sem a utilização de terapias virais são denominados controladores de elite. ${ }^{22}$

Os EC são capazes de manter sua carga viral indetectável por um período longo de tempo sem a utilização de tratamentos antirretrovirais. Esse controle natural da replicação do vírus sem uso de TARV é exclusivo desse grupo, o qual compreende menos de $1 \%$ da população de infectados. ${ }^{20}$ Estudos realizados a fim de descobrir o desenvolvimento do controle viral em hospedeiros EC visam o desenvolvimento de uma cura. ${ }^{20}$

A TARV para o HIV não é uma cura. No entanto, estudos sugerem que a TARV, iniciada precocemente durante a infecção primária, pode induzir o controle pós-tratamento da infecção pelo HIV com o RNA do HIV mantido em $<50$ cópias por $\mathrm{mL}$. De acordo com o mesmo estudo, as contagens de células $\mathrm{T} \mathrm{CD}_{4}{ }^{+}$dos pacientes aumentaram durante a TARV de uma mediana de 502 células $/ \mathrm{mm}^{3}$ a uma mediana de 927 células $/ \mathrm{mm}^{3}$ e eles mantiveram uma contagem de células $\mathrm{T} \mathrm{CD} 4^{+}$quase normal após o tratamento (mediana de 827 células $/ \mathrm{mm}^{3}$ ). Acredita-se que esse fenômeno pode ser considerado como um EC por meio do uso de TARV. ${ }^{20,21}$

Uma das hipóteses para que um indivíduo tenha o perfil de controlador de elite é a mutação CCR5 delta 32, essencial no momento da interação vírus-célula hospedeira para que haja ligação com esse correceptor, portanto, em sua ausência ou baixa expressão, a entrada do vírus para o meio intracelular fica prejudicada. A mutação CCR5 delta 32, ou CCR5 $\triangle 32$ envolve a deleção de 32 pares de bases. A deleção causa um frameshift, ou seja, uma mudança na fase de leitura durante a tradução, afetando as últimas três regiões transmembranas do CCR5, mais especificamente no segundo loop extracelular no qual ocorre o sítio de ligação da proteína $G$ responsável pela transdução de sinal celular. O alelo mutante contém 215 aminoácidos, enquanto o alelo selvagem possui 352 aminoácidos, o que gera então uma proteína truncada que não pode ser detectada na superfície celular. ${ }^{23,24}$

De acordo com alguns estudos, certos genótipos do antígeno leucocitário humano (HLA), incluindo $B^{\star} 27$ e $B^{\star} 57$, são frequentes na população dos controladores de elite, fato que sugere um papel importante dos linfócitos $\mathrm{T}$ citotóxicos $\mathrm{CD} 8^{+}$no controle da replicação do HIV nesses controladores. Ao se comparar as respostas das células $\mathrm{T}$ nos controladores de elite em comparação com os progressores crônicos, foi observado que os linfócitos $\mathrm{T} \mathrm{CD}^{+}$desempenham papel predominante na regulação da replicação viral nos indivíduos ECs. Essa resposta envolve a morte de células $\mathrm{T} \mathrm{CD} 4^{+}$autólogas infectadas pelo HIV por células $\mathrm{T} \mathrm{CD}^{+}$, o que é um dos correlatos mais fortes do controle identificado até o momento. Além disso, o aumento na expressão das moléculas efetoras das células $\mathrm{T} \mathrm{CD}^{+}$, perforina e granzima $\mathrm{B}$, está intimamente associado à proteção nos ECs. Em contraste, as células T 
$\mathrm{CD}^{+}$específicas para HIV de progressores crônicos proliferam pouco, e tem capacidade citotóxica muito baixa. ${ }^{14,25}$

Receptores Toll-Like (TLRs) estão envolvidos no reconhecimento inato de muitos microrganismos, incluindo o HIV-1 por meio de padrões moleculares associados ao patógeno (PAMPs). Polimorfismos nesses receptores têm sido mostrados para influenciar os desfechos da doença em diferentes doenças infecciosas. ${ }^{26}$ Embora os polimorfismos em TLR9 tenham se mostrado associados à infecção rapidamente progressiva pelo HIV-1, estudos não encontraram relação entre os polimorfismos da TLR ao controle de elite da infecção pelo HIV-1. Segundo outros estudos, a endocitose HIV-1 têm ativado as células dendríticas plasmocitoides (pDCs) por TLRs levando à secreção de interferon-alfa e outras citocinas inflamatórias que podem ter propriedades antivirais. A infecção pelo HIV-1 pode levar à queda da regulação das proteínas HLA-A e HLA-B na superfície das células infectadas, um processo que pode desencadear a ativação celular NK. ${ }^{27}$

A comunidade científica tem estudado indivíduos que conseguem de alguma forma realizar o controle viral de acordo com o histórico genético do paciente, em que são representados os alelos HLA-B27 antígeno, no entanto, ainda existem pacientes ECs em que as células T $\mathrm{CD}^{+}$entram em declínio durante o período de domínio ou perda do controle de replicação viral. A ativação imunológica crônica e eventos cardiovasculares em ECs também são fatores observados por estarem associados à perda de células $\mathrm{T}$ $\mathrm{CD}^{+}$. De acordo com alguns estudos com grandes coortes de soroconversão, 25\% dos
ECs deixaram de ser controladores de elite 20 anos após soroconversão, existindo casos de progressão da doença em pacientes que já foram controladores de elite. ${ }^{16}$

Uma abordagem terapêutica potencial que vem sendo levantada no meio científico, é a transferência de células $\mathrm{T}$, específicas para vírus de ECs que apresentam controle imune-mediado, para pacientes com infecção não controlada. Por outro lado, essa abordagem sugere que a transferência adotiva de linfócitos de um controlador de elite infectado com HIV para um paciente infectado com HIV com doença progressiva pode ser capaz de afetar o sistema imunológico do receptor de forma positiva e negativa. Estudos com células T alogênicas específicas de vírus, principalmente células $\mathrm{T}$ $\mathrm{CD}^{+}$, transferidas para pacientes com reativação de Citomegalovírus, Vírus Epstein-Barr e outros vírus após o transplante de células-tronco, mostraram que essas células transferidas podem induzir com segurança uma redução significativa das cargas virais. Poucos estudos semelhantes utilizando células específicas do vírus foram realizados em pacientes infectados pelo HIV. ${ }^{25}$

\section{CONSIDERAÇões FINAIS}

Os mecanismos biológicos envolvidos no controle da infecção pelo HIV e na progressão para a AIDS entre os ECs ainda não estão esclarecidos. Sejam esses mecanismos mutações nos genes que expressam correceptores fundamentais para a entrada do vírus na célula, ou outros fatores genéticos que envolvem a relação patógeno-hospedeiro, é de fundamental importância o estudo aprofundado dos mecanismos relacionados 
ao controle espontâneo e natural da replicação viral e da manutenção dos níveis de linfócitos $\mathrm{T} \mathrm{CD} 4^{+}$. Esse estudo pode fornecer informações críticas sobre as dinâmicas ví- rus-hospedeiro e revelar o alvo ideal de um novo fármaco ou vacina, ou seja, é a chave para o desenvolvimento de novas abordagens terapêuticas.

\section{REFERÊNCIAS}

1. Ministério da Saúde (BR). Manual técnico para o diagnóstico da infecção pelo HIV em adultos e crianças. 4th ed. Martinazzo AG, editor. Secretaria de Vigilância em Saúde. Brasília: Editora Ministério da Saúde, 2018, p. 148.

2. Gottlieb GS, Raugi DN, Smith RA. 90-90-90 for HIV-2? Ending the HIV-2 epidemic by enhancing care and clinical management of patients infected with HIV-2. Lancet HIV. 2018;5(7):e390-e399

3. Cihlar T, Fordyce M. Current status and prospects of HIV treatment. Curr Opin Virol. 2016;18:50-56

4. Ministerio da Saúde (BR). Boletim Epidemiológico HIV/AIDS da Secretaria de Vigilância em Saúde - Ministério da Saúde. Boletim Epidemiológico. 2019; 48:1.52.

5. Mehrbod P, Ande SR, Alizadeh J, Rahimizadeh S, Shariati A, Malek H, et al. The roles of apoptosis, autophagy and unfolded protein response in arbovirus, influenza virus, and HIV infections. Virulence. 2019;10(1):376-413

6. Veras RP, Barreto ML, Almeida N Filho, Barata RB. orgs. Epidemiologia: contextos e pluralidade [online]. Rio de Janeiro: Editora FIOCRUZ, 1998. 172 p. Epidemiológica series, $\mathrm{n}^{\circ} 4$.

7. Bhatti AB, Usman M, Kandi V. Current Scenario of HIV/AIDS, Treatment Options, and Major Challenges with Compliance to Antiretroviral Therapy. Cureus. 2016;8(3):e515

8. Brito AM, Castilho EA, Szwarcwald CL. AIDS e infecção pelo HIV no Brasil: uma epidemia multifacetada. Rev. Soc. Bras. Med. Trop. 2000;34 (2): 207-17

9. Lima YAR, Alves MDF. O sistema imune da mucosa do trato genital feminino e o impacto das doenças sexualmente transmissíveis. Revista de Patologia Tropical. 2008; 37 (4): 295-309

10. Focaccia R, Veronesi R. Tratado de infectologia. 5th ed. Veronesi Ricardo, editor. Vol. 1. São Paulo: Editoria Atheneu; 1-2320, 2015.

11. Conway JM, Perelson AS. Post-treatment control of HIV infection. Proc Natl Acad Sci U S A. 2015;112(17):5467-72

12. Machado FES, Nunes LCT, Barbosa MXS, Silva ALM, Grangeiro ARS. Controladores de Elite e Hiv: Uma Revisão de Literatura. Revista Multidisciplinar Em Saúde, 2(2): 56.

13. Tibúrcio AS. Pacientes HIV-positivo não progressores em longo prazo: dois casos. J bras Doenças Sex Transm. 2009; 21 (2): 87-90.

14. Ferreira RCS, Riffel A, Sant’ana AEG. HIV: mecanismo de replicação, alvos farmacológicos e inibição por produtos derivados de plantas. Quím. Nova. 2010; 33 (8): 1743-55

15. Sáez-Cirión A, Bacchus C, Hocqueloux L, Avettand-Fenoel V, Girault I, Lecuroux C, et al. Posttreatment HIV-1 controllers with a long-term virological remission after the interruption of early initiated antiretroviral therapy ANRS VISCONTI Study. PLoS Pathog. 2013;9(3):e1003211

16. Okulicz JF, Marconi VC, Landrum ML, Wegner S, Weintrob A, Ganesan A, et al. Clinical outcomes of elite controllers, viremic controllers, and long-term nonprogressors in the US Department of Defense HIV natural history study. J Infect Dis. 2009;200(11):1714-23

17. Olson AD, Meyer L, Prins M, Thiebaut R, Gurdasani D, Guiguet M, et al. An evaluation of HIV elite controller definitions within a large seroconverter cohort collaboration. PLoS One. 2014;9(1):e86719 
18. Machmach K, Leal M, Gras C, Viciana P, Genebat M, Franco E, et al. Plasmacytoid dendritic cells reduce HIV production in elite controllers. J Virol. 2012;86(8):4245-52

19. Pereyra F, Palmer S, Miura T, Block BL, Wiegand A, Rothchild AC, et al. Persistent low-level viremia in HIV-1 elite controllers and relationship to immunologic parameters. J Infect Dis. 2009;200(6):984-90

20. Cockerham LR, Hatano H, Deeks SG. Post-Treatment Controllers: Role in HIV "Cure" Research. Curr HIV/AIDS Rep. 2016;13(1):1-9

21. Sáez-Cirión A, Pancino G. HIV controllers: a genetically determined or inducible phenotype? Immunol Rev. 2013;254(1):281-94

22. Fenwick C, Joo V, Jacquier P, Noto A, Banga R, Perreau M, et al. T-cell exhaustion in HIV infection. Immunol Rev. 2019;292(1):149-163

23. Samson M, Libert F, Doranz BJ, Rucker J, Liesnard C, Farber CM, et al. Resistance to HIV-1 infection in caucasian individuals bearing mutant alleles of the CCR-5 chemokine receptor gene. Nature. 1996;382(6593):722-5

24. Dean M, Carrington M, Winkler C, Huttley GA, Smith MW, Allikmets R, et al. Genetic restriction of HIV-1 infection and progression to AIDS by a deletion allele of the CKR5 structural gene. Hemophilia Growth and Development Study, Multicenter AIDS Cohort Study, Multicenter Hemophilia Cohort Study, San Francisco City Cohort, ALIVE Study. Science. 1996;273(5283):1856-62

25. Migueles SA, Chairez C, Lin S, Gavil NV, Rosenthal DM, Pooran M, et al. Adoptive lymphocyte transfer to an HIV-infected progressor from an elite controller. JCI Insight. 2019;4(18):e130664.

26. Ferraz EG, Silveira BBB, Sarmento VA, Santos JN. Receptores Toll-Like: ativação e regulação da resposta imune. Rev. gaúch. odontol. (Online). 2011; 59(3): 483-90

27. O’Brien M, Manches O, Bhardwaj N. Plasmacytoid dendritic cells in HIV infection. Adv Exp Med Biol. 2013;762:71-107

\section{DAdOS DOS AUTORES}

\section{Larissa De Oliveira Rosa Marques}

Graduanda em Biomedicina na Universidade Federal de Goiás (UFG), Goiânia/GO - Brasil. larissa313@gmail.com

\section{Gabriel Oliveira Santana}

Graduado em biomedicina pela Universidade Paulista (UNIP).gabri.oli@hotmail.com

\section{Ana Karoline Silva Oliveira}

Mestre em assistência e avaliação em saúde pela Universidade Federal de Goiás (UFG), Goiânia/ GO - Brasil. Pesquisadora da Universidade Federal de Goiás (UFG), Goiânia/GO - Brasil. eukarolineoliveira@gmail.com

\section{Juliana Menara de Souza Marques}

Doutoranda pelo Programa de pós-graduação em Biologia da relação parasito-hospedeiro da Universidade Federal de Goiás (UFG), Goiânia/GO - Brasil. Docente na Universidade Paulista (UNIP). jully_menara@hotmail.com 


\section{Xisto Sena Passos}

Doutor em medicina tropical. Docente na Universidade Paulista (UNIP). xisto.passos@docente. unip.br

\section{Antonio Márcio Teodoro Cordeiro Silva}

Doutor em biologia celular e molecular pela Universidade Federal de Goiás (UFG), Goiânia/GO Brasil. Docente na Pontifícia Universidade Católica de Goiás, Goiânia/GO - Brasil. marciocmed@ gmail.com

\section{Lucas Luiz de Lima SiLva}

Doutor em biologia da relação parasito-hospedeiro pela Universidade Federal de Goiás (UFG), Goiânia/GO - Brasil. Docente na Universidade Paulista. lucas.silva@docente.unip.br

Submetido em: 16-7-2020

Aceito em: 12-8-2021 